\title{
Application of Tuckman's Model in the Community Folk Team Management in Community Education
}

\author{
Jie ZHEN \\ East China University of Political Science and Law, Shanghai, China \\ jetzhen@163.com
}

\begin{abstract}
Keywords: Tuckman's model, Community education, Community folk team, non-governmental organization
\end{abstract}

\begin{abstract}
Tuckman's model describes the five stages of group development. Each stage has its own characteristics and it should be managed according to the features. The model has been widely used in various of organizations. We apply Tuckman's model to the community non-governmental organization with the specific situation of China. And then we obtain some better results and form the method of operation. This paper sums up the practical experience from using the model to the non-governmental organization in order to provide a reference for other community group development.
\end{abstract}

\section{Overview of the Tuckman's Model}

The team develops and changes all the time. Tuckman's model describing the stages of group development was publicized by Bruce W Tuckman in 1965 and revised in 1977. It presents the well known five stages of forming, storming, norming, performing, and adjourning. The model has a profound influence on the development of organization theory.

\section{Forming}

The first stage of the model is 'testing and dependence' (Tuckman 1965). In this stage, the individuals attempts to discover the nature and boundaries for interpersonal and task by testing interpersonal relationship, attempts to define the situation, establishes a proper relationship with others, creates ground rules and exchanges information. In this stage, team's objective, structure, leadership are uncertain. The team members explore behavior norm that can be accepted by groups (Tuckman, 1965).

\section{Storming}

The second stage of the model is 'resistance to group influence and task requirements' (Tuckman, 1965). The group identifies intergroup conflict. This phase is characterized by lack of unity and polarization around interpersonal issues. In this stage, group members become hostile toward one another or express their individuality and resisting the formation of group structure (Bone bright, 2009).

\section{Norming}

The third stage of the model is 'openness to other group members'. (Tuckman, 1965). In this stage, ingroup feeling and cohesiveness develop. New standards evolve and new roles are established. Open exchange of relevant interpretations, intimate, personal opinions are expressed (Tuckman, 1965). Task conflicts are avoided in an effort to insure harmony (Bone bright, 2009).

\section{Performing}

The fourth stage of the model is 'constructive action' (Tuckman 1965). In this stage, role becomes flexible and functional. And structural issue has been resolved. Also, structure can support task performance. Interpersonal structure becomes the tool of task activities. And group energy is channeled into the task. In this stage, solutions can emerge. 


\section{Adjourning}

The fifth stage of the model is 'disengagement' (Tuckman, 1965). Anxiety about separation and termination, sadness, feelings toward leader and group members. The group have to evaluate itself. At this stage, the team controls members' behaviors through the implementation of positive and negative motivation and is able to recruit new members after the old members leave. In this stage, some teams may continue, some teams' interrelations begin to loose until the dissolution.

The development of group is a dynamic process. Most groups changes frequently. Sometimes several stages may also coexist at the same time, sometimes may leap forward one or two stages, occasionally even some team will be back to the previous stage (Stephen, 2003). Tuckman's model provides a good theoretical basis for the study of team formation management. This article from the government's perspective, study the practice of Tuckman's model in the community folk team.

\section{The Development of Community Folk Team}

In order to adapt to the continuous development of the society, residents' demand to the knowledge gradually increases, community folk organizations which try to meet these demands are booming at a very rapid momentum. At the same time, in the process of promote the regional culture inheritance in China, a number of folk self-management organization emerge as the times require. Many citizens learn knowledge and show themselves by participating in these teams. The organizations promote community cultural prosperity and play an important role in the construction of a harmonious community. We define it as community folk team.

Community folk team is a non-profit organizations, its task is to improve the quality of life by learning in community. At the same time, it also performs some social function such as entertainment, sporting activities and public services. Team members are from the community residents who have common interests, hobbies and form a team voluntarily. A group contains five to forty members ordinarily. Usually the team has a trainer or leader. The leader is elected by the members democratically.

However, these organizations are still exist some problems in the development. Firstly, community folk teams have "inherent problems", such as the lack of management system necessary, the lack of team management experience, no plan and long-term goal. Secondly, there would be no guarantee for location of activities, activity time, and stage for show. Thirdly, community team members are mainly from local residents. The managers of the groups lack the art of leadership and the spirit of innovation, those lead to team develop slowly.

In order to build the learning society, it should need that the government guides the community folk team to create a learning organization, makes the team activities have more mass basis and vitality, which injects new vitality into the development of community education. Finally it will become an important part of learning society of lifelong learning and lifelong education.

\section{Cultivating Strategy of the Community Folk Team}

\section{Management Strategies of Forming Stage}

\section{Clearing Objectives, Giving Support in the Capital, Site and Personnel.}

In the primary stage of team development, most residents of the community for the same hobbies organize to make activities together. Members have high enthusiasm and motivation to entertain. Objective, structure, leadership of the team are uncertain and the team has no planning and long-term objectives. Lack of resources and location of activities, activity time is not regular and cannot be guaranteed, condition of activities and facilities is very simple and crude. So the management focus of this phase is to clear the team's expectations, encourage and help the team to make goals and work plans, develop team activities. 


\section{Management Strategies of Storming Stage}

\section{Building Platform, Guiding in Classification, Highlighting the Characteristics.}

In the second stage, the objectives of the team begin to get agreement in team members. In this process, the belonging to the team and a sense of identity of members is further strengthened. The expectation of serving the community will rise, but the team culture has not yet formed. According to these characteristics, managers should encourage the team leader and team members to develop a clear plan for self-development, which should be consistent with team development goals. Consciously creating conditions to help them to grow, creating a platform, expanding its space activities, attracting them to participate in community construction. Guiding the team in classification forms the unique culture of the each team.

\section{Management Strategies of Norming Stage}

\section{Training the Core Members, Encouraging Innovation.}

In the third stage, team members begin to form a close relationship between themselves. They will have a strong team sense of identity and friendship. The motivation of team members who joining the team is changed from enjoyment to get happiness though service to others. This stage focuses on formatting team spirit. During the formation of team cohesion and team spirit, team leader and backbone play an important role. So it is important to pay attention to train team's core members. In this stage, the teams become matured, can be leaded to keep pace with the times, be closed to the residents' lives. In this stage, the members in the community should develop mutual help and improvement among the different team. Gradually, they will innovate the learning style of the team; lift the learning efficiency of the team.

\section{Management Strategies of Performing Stage}

\section{Using the Method of Evaluation to Encourage, Lifting the Self-Manage Ability of the Team.}

In this stage, the ability and high cohesion of the team is obviously enhanced. The team makes a contribution in building civilized communities, plays a role for the maintenance of community harmony and stability, and wins the recognition of the society. According to Maslow's hierarchy of needs, respect and self realization need become the main motivation of this stage of team members to participate in activities. The incentive should reward team achievement, also recognize individual contributions. In this stage, a lot of loose and highly arbitrary groups have gradually grown up to the folk teams having some self-management ability and discipline after cultivated.

\section{Management Strategies of Adjourning Stage}

\section{People-Oriented, Strengthening Humanistic Care.}

After several years of cultivation, the management systems of some community folk teams become more perfect, which produces a batch of brand team with well- known characteristics in the community, the city and even in the country. They integrate the existing resources of community and adopt a variety of novel form to guide the community residents to participate in community construction by using the propaganda position in community; however, some team also appear phenomena such as disorganized, loss of members, dissolution etc.. It is encouraged that the team do succession planning and actively recruit new members. In the adjustment phase, it should pay attention to strengthen the humanistic care, highlight the concept of people-oriented, understand the change of emotion of members, improve the enthusiasm and creativity of the team and stimulate the potential of team members.

\section{Acknowledgement}

This research was supported by 2015 Shanghai Social Sciences Planning Project under Grant 2015JG009-BGL307 and 2017 National Social Science Foundation under Grant 17BGL099. 


\section{References}

[1] Tuckman, B. W. Developmental Sequence in Small Groups [J]. Psychological Bulletin, 1965(6): 384-399.

[2] Tuckman, B.W. and M.A. Jensen. Stages of Small-group Development Revisited [J]. Group and Organization Studies, 1977 (4): 419-427.

[3] Bone bright D A. 40 Years of Storming: a Historical Review of Tuckman's Model of Small Group Development [J]. Human Resource Development International. 2010(13)4: 111-120

[4] Robbins S P., Judge T A. organizational Behavior. Renmin University of China press. 2003

[5] Robbins, H., and M. Finley. Why Teams don’t Work. San Francisco: Berrett-Koehler.2000.

[6] Nash, S., and C. Bolin. Teamwork from the Inside Out: Fieldbook. Palo Alto, CA: Davies-Black2003. 